\title{
In vivo molecular neuroimaging of glucose utilization and its association with fibrillar amyloid- $\beta$ load in aged APPPS1-21 mice
}

Ann-Marie Waldron ${ }^{1}$, Cindy Wintmolders ${ }^{2}$, Astrid Bottelbergs ${ }^{2}$, Jonathan B. Kelley², Mark E. Schmidt ${ }^{2}$, Sigrid Stroobants ${ }^{1,3}$, Xavier Langlois $^{2}$ and Steven Staelens ${ }^{1 *}$

\begin{abstract}
Introduction: Radioligand imaging is a powerful in vivo method to assess the molecular basis of Alzheimer's Disease. We therefore aimed to visualize the pathological deposition of fibrillar amyloid- $\beta$ and neuronal dysfunction in aged double transgenic mice.

Methods: Using non-invasive positron emission tomography (PET) we assessed brain glucose utilization with $\left[{ }^{18} \mathrm{~F}\right] \mathrm{FDG}$ and fibrillar amyloidosis with $\left[{ }^{11} \mathrm{C}\right] \mathrm{PiB}$ and $\left[{ }^{18} \mathrm{~F}\right] \mathrm{AV} 45$ in 12 month old APPPS1-21 $(n=10)$ mice and their age-matched wild-type controls $(n=15)$. PET scans were analyzed with statistical parametric mapping (SPM) to detect significant differences in tracer uptake between genotypes. After imaging, mice were sacrificed and ex vivo measures of amyloid- $\beta$ burden with immunohistochemistry as well as glucose utilization with $\left[{ }^{14} \mathrm{C}\right]-2 \mathrm{DG}$ autoradiography were obtained as gold standards.
\end{abstract}

Results: Voxel-wise SPM analysis revealed significantly decreased $\left[{ }^{18}\right.$ F]FDG uptake in aged APPPS1-21 mice in comparison to WT with the thalamus $(96.96 \%$, maxT $=3.35)$ and striatum $(61.21 \%$, maxT $=3.29)$ demonstrating the most widespread reductions at the threshold of $p<0.01$. $\left[{ }^{11} \mathrm{C}\right] \mathrm{PiB}$ binding was significantly increased in APPPS1-21 mice, most notably in the hippocampus $(87.84 \%$, max $T=7.15)$ and cortex $(69.08 \%$, maxT $=7.95)$, as detected by SPM voxel-wise analysis at the threshold of $p<0.01$. Using the same threshold $\left[{ }^{18} \mathrm{~F}\right] \mathrm{AV} 45$ uptake was comparably lower with less significant differences. Compared to their respective ex vivo equivalents $\left[{ }^{18} \mathrm{~F}\right] \mathrm{FDG}$ demonstrated significant positive correlation to $\left[{ }^{14} \mathrm{C}\right] 2-\mathrm{DG}$ autoradiography $(r=0.67, p<0.0001)$ while $\left[{ }^{11} \mathrm{C}\right] \mathrm{PiB}$ and $\left[{ }^{18} \mathrm{~F}\right] \mathrm{AV} 45$ binding did not correlate to ex vivo immunohistochemistry for amyloid- $\beta$ ( $r=0.25, p=0.07$ and $r=0.17, p=0.26$ respectively). Lastly no correlation was observed between regions of high amyloid burden and those with decreased glucose utilization ( $r=0.001, p=0.99)$.

Conclusions: Our findings support that fibrillar amyloid- $\beta$ deposition and reduced glucose utilization can be visualized and quantified with in vivo $\mu$ PET imaging in aged APPPS1-21 mice. Therefore, the combined use of $\left[{ }^{18} \mathrm{~F}\right] \mathrm{FDG}$ and amyloid $\mu \mathrm{PET}$ imaging can shed light on the underlying relationship between fibrillar amyloid- $\beta$ pathology and neuronal dysfunction.

\footnotetext{
* Correspondence: steven.staelens@uantwerpen.be

${ }^{1}$ Molecular Imaging Center Antwerp, University of Antwerp, Campus Drie

Eiken - UC, Universiteitsplein 1, 2610, Wilrijk, Antwerp, Belgium

Full list of author information is available at the end of the article
}

(c) 2015 Waldron et al. Open Access This article is distributed under the terms of the Creative Commons Attribution 4.0 International License (http://creativecommons.org/licenses/by/4.0/), which permits unrestricted use, distribution, and reproduction in any medium, provided you give appropriate credit to the original author(s) and the source, provide a link to the Creative Commons license, and indicate if changes were made. The Creative Commons Public Domain Dedication waiver (http://creativecommons.org/publicdomain/zero/1.0/) applies to the data made available in this article, unless otherwise stated. 


\section{Introduction}

Nuclear medicine imaging of the human brain afflicted by Alzheimer's Disease (AD) has progressed over the last decades from non-specific markers of neurodegeneration, such as altered metabolism [1, 2], blood flow [3], and inflammation $[4,5]$, to disease-specific markers of amyloid- $\beta$ [6] and tau tangles [7] believed to instigate the pathologic cascade. For diagnostic purposes, the functional metabolic marker $\left[{ }^{18} \mathrm{~F}\right]$ fluorodeoxyglucose $\left(\left[{ }^{18} \mathrm{~F}\right] \mathrm{FDG}\right)$ remains the most routinely used positron emission tomography (PET) radioligand [8] but the more novel amyloid- $\beta$ tracers are increasingly used since their recent clinical approval (Amyvid, Neuraceq, and Vizamyl) and growing availability. In clinical studies the combined use of these tracers allows the non-invasive tracking of $\mathrm{AD}$ from the early pathologic events of amyloid- $\beta$ deposition to the later neurodegenerative mechanisms related to clinical decline and have proved seminal in understanding the natural history of AD.

Given the clinical utility of $\left[{ }^{18} \mathrm{~F}\right] \mathrm{FDG}$ and amyloid tracers, there is considerable interest in back-translating their success to preclinical investigations. A number of transgenic mouse models of cerebral amyloidosis are readily available and are generally created by the manipulation of the genes involved in amyloid processing [9]. While investigation of these models has led to a greater understanding of amyloid-related disease mechanisms, they are limited by the primary use of ex vivo methods to assess brain pathology. The application of small animal PET imaging ( $\mu \mathrm{PET})$ to preclinical research allows for the simultaneous longitudinal monitoring of a number of physiological processes in a subject over time and can thus enhance the translational value of animal studies. Despite having lower affinity for fibrillar amyloid$\beta$ in animal models $[10,11]$, amyloid tracers have successfully monitored progressive amyloidosis in a number of transgenic cerebral amyloidosis models [11-17] and have been shown sensitive enough to detect treatment-induced reductions in plaque load with an anti-amyloid antibody [11] and a $\gamma$-secretase inhibitor [18]. Although $\left[{ }^{18}\right.$ F]FDG is a better-established tracer, its ability to detect cerebral hypometabolism in amyloidosis models with $\mu \mathrm{PET}$ is debated. Early investigations of glucose utilization in transgenic models with $\left[{ }^{18} \mathrm{~F}\right] \mathrm{FDG}$ focused on the highresolution technique of ex vivo autoradiography. With this method a number of models were shown to have reductions in $\left[{ }^{18} \mathrm{~F}\right] \mathrm{FDG}$ uptake in brain regions with homology to those affected in clinical AD [19-23]. However when applied in vivo with $\mu$ PET scanners the majority of studies have reported either unchanged [24, 25] or increased $\left[{ }^{18} \mathrm{~F}\right]$ FDG [26-28] uptake in transgenic models. Given the lower resolution of $\mu \mathrm{PET}$ in comparison to autoradiography, decreased sensitivity may indeed mask small regional decreases in $\left[{ }^{18} \mathrm{~F}\right] \mathrm{FDG}$ uptake between genotypes
[29]. However these discrepancies may also be accounted for by methodological factors [30] in addition to strain differences. More recently in vivo hypometabolism in amyloidosis models has been described [31-33].

The assessment of glucose utilization is a necessary adjunct to amyloid imaging to unravel the relationship between amyloid- $\beta$ and neuronal dysfunction. While amyloid imaging may provide a read-out of target engagement for amyloid targeted therapies, such therapies should also be tested for their ability to prevent loss of neuronal function. Moreover, monitoring therapeutic efficacy with $\left[{ }^{18} \mathrm{~F}\right] \mathrm{FDG}$ would provide a valuable in vivo biomarker for non-amyloid targeted therapies, such as neuroprotective strategies or symptomatic relief. We have previously investigated the use of $\left[{ }^{18} \mathrm{~F}\right] \mathrm{FDG}$ and the amyloid tracer $\left[{ }^{18} \mathrm{~F}\right]$ florbetapir in the double transgenic TASTPM mouse model and demonstrated significantly increased retention of $\left[{ }^{18} \mathrm{~F}\right]$ florbetapir and significantly lower $\left[{ }^{18} \mathrm{~F}\right] \mathrm{FDG}$ uptake in these aged animals [33]. We aimed here to extend our findings using a different double transgenic model of amyloidosis and confirming our in vivo findings with ex vivo $\left[{ }^{14} \mathrm{C}\right] 2-\mathrm{DG}$ autoradiography. We chose to investigate APPPS1-21 mice as they have demonstrated synaptic alterations $[34,35]$ and cognitive impairment $[36,37]$ and, thus, represent an interesting model for measuring neuronal dysfunction. We additionally utilized $\left[{ }^{11} \mathrm{C}\right] \mathrm{PiB}$ and $\left[{ }^{18} \mathrm{~F}\right] \mathrm{AV} 45$ binding [38] in these mice as an in vivo measure of fibrillar amyloid- $\beta$ burden.

\section{Methods}

\section{Animals}

We employed APPPS1-21 $(n=10)$ double transgenic mice that co-express the human Swedish double APP mutation KM670/671NL and the human mutated PS1 L166P driven by the neuron-specific Thy- 1 promoter element. Due to these mutations APPPS1-21 mice undergo accelerated and severe disease pathogenesis. Amyloid- $\beta$ deposition begins as early as six weeks of age and at later stages these mice have extensive dense core plaque pathology [36]. Wild-type littermates (WT) were used as controls (C57BL6J, $n=15$ ) and all animals were female. The animals were kept under environmentally controlled conditions ( $12 \mathrm{~h}$ light/dark cycle, $20-24{ }^{\circ} \mathrm{C}$ and $40-70 \%$ relative humidity) in individually ventilated cages with food and water ad libitum. Animals were group-housed and received environmental enrichment. Mice were 12 months old at the time of imaging. The study protocol was approved by the local Animal Experimental Ethical Committee of the University of Antwerp, Belgium (2012-25) where the in vivo experiments were performed. All animal studies were ethically reviewed and carried out in accordance with European Directive 86/609/EEC Welfare and Treatment of Animals. 


\section{Tracer radiosynthesis}

$\left[{ }^{11} \mathrm{C}\right] \mathrm{PiB}$ was synthesized according to the one step method under neutral conditions as described previously [38]. $\left[{ }^{18} \mathrm{~F}\right]$ FDG was prepared using a cassette based GE Fastlab synthesis module (GE Healthcare, Diegem, Belgium). $\left[{ }^{18} \mathrm{~F}\right]$-AV45 was synthesized from the tosyloxy precursor AV-105 by modification of the method as described by Yao and coworkers [39].

\section{PET image acquisition and analysis}

Static $\mu$ PET scans (Siemens Preclinical Solution, Knoxville, TN, USA) were acquired after intravenous tracer injection and a conscious uptake period. For $\left[{ }^{18} \mathrm{~F}\right] \mathrm{FDG}$, mice received $18.65 \pm 0.62 \mathrm{MBq}$ (45 min uptake, 20 min scan). Prior to scanning, animals were fasted overnight for 8-12 hours and blood glucose levels were monitored by a diagnostic assay. For $\left[{ }^{11} \mathrm{C}\right] \mathrm{PiB}$, mice received $4.28 \pm 1.06 \mathrm{MBq}$ (20 min uptake, 30 min scan) while for $\left[{ }^{18} \mathrm{~F}\right] \mathrm{AV} 45$ mice received $17.8 \pm 0.92 \mathrm{MBq}$ (30 min uptake, 20 min scan). Anesthesia was induced by inhalation of isoflurane (5\% for induction, and $2 \%$ for maintenance during preparation and scanning) supplemented with oxygen. The core body temperature of the animals was maintained via a temperature controlled heating pad.

$\mu \mathrm{PET}$ data was reconstructed with two-dimensional ordered subsets expectation maximization (OSEM2D) [40] algorithm using four subsets and 16 iterations following Fourier rebinning (FORE) [41]. The energy and timing window was set to $350-650 \mathrm{keV}$ and $3.432 \mathrm{nsec}$, respectively. The $\mu$ PET images were reconstructed on a $128 \times 128 \times 159$ grid with a pixel size of $0.776 \mathrm{~mm}$ and a slice thickness of $0.796 \mathrm{~mm}$. Normalization, dead time, randoms, CT-based attenuation and single scatter simulation (SSS) [42] corrections were applied. A five min CT was acquired subsequent to all PET scans using a 220 degree rotation with 12 - rotation steps; voltage and amperage were set to $80 \mathrm{keV}$ and $500 \mathrm{uA}$, respectively.

Volume-of-interest (VOI) and voxel-wise analysis (statistical parametric mapping) methods were performed on reconstructed images using PMOD v3.3 (PMOD technologies, Zurich, Switzerland) and SPM8 (Wellcome Trust Centre, London, UK). Individual PET images were spatially normalized into the space of a predefined mouse brain template [43] by matching the individual animal specific CT to the template CT and applying the same transform to the PET which is by default matched to its $\mathrm{CT}$ via the PET/CT scanner hardware. Thereafter, extracerebral activity was removed through the use of a brain mask derived from the Mirrione $\mathrm{T}_{2}$-weighted MR template (a priori matched with the same CT template) [43] whereby all voxels outside the brain mask were set to zero intensity and voxels inside the mask were unaltered. For an absolute measure of tracer uptake, normalized images were scaled according to the percent injected dose for $\left[{ }^{11} \mathrm{C}\right] \mathrm{PiB}$ and $\left[{ }^{18} \mathrm{~F}\right] \mathrm{AV} 45$ (tissue uptake[kBq/cc]/injected dose[kBq] * 100) and glucose-corrected percent injected dose for $\left[{ }^{18} \mathrm{~F}\right]-\mathrm{FDG}$ (tissue uptake[kBq/cc] * blood glucose/injected dose[kBq] *100).

For VOI analysis, processed images were subsequently co-registered with a predefined mouse brain VOI template (encompassing all relevant brain regions) aligned with the aforementioned Mirrione CT/MRI atlas and tracer uptake values were extracted for each delineated VOI. With this approach regional values are quantified as the average uptake over the total number of voxels in a VOI.

For voxel-wise analysis of tracer uptake between genotypes, a two-sample unpaired t-test was applied to normalized and scaled images, with a significance threshold of $p<0.01$ for all tracers with an extent threshold of 100 voxels $\left(48 \mathrm{~mm}^{3}\right)$, uncorrected for multiple comparisons. Quantification of this voxelwise analysis was investigated by employing two indices: 1$)$ the number of significant voxels in a VOI relative to the total number of voxels (\% sign); and 2) the maximal $\mathrm{T}$ value (maxT). For qualitative purposes $\mathrm{T}$-maps were smoothed with an isotropic Gaussian kernel with $0.5 \mathrm{~mm}$ full width at half maximum (FWHM) subsequent to analysis.

\section{Ex vivo gold standard evaluation}

Mice were 13 months old (end of life). Mice were fasted for $12 \mathrm{hr}$ to stabilize plasma glucose levels prior to an intraperitoneal injection of $0.148 \mathrm{MBq}$ (weight adjusted) $\left[{ }^{14} \mathrm{C}\right] 2-\mathrm{DG}$. After a conscious uptake period of $45 \mathrm{~min}$, mice were sacrificed by decapitation and the brains rapidly removed. After decapitation plasma glucose was measured by a diagnostic assay.

For autoradiography, the left brain hemisphere was frozen in cooled 2-methylbutane $\left(-30{ }^{\circ} \mathrm{C}\right.$ on dry ice) for approximately one min. This hemisphere was then covered in tissue embedding medium which was allowed to cool to $-20{ }^{\circ} \mathrm{C}$. Coronal sections (20 $\mu \mathrm{m}$ thick) were sliced in triplicate by a cryostat and thaw mounted on glass microscope slides. The slides were immediately placed on a heating plate $\left(60{ }^{\circ} \mathrm{C}\right)$ for five to ten min to prevent diffusion of $\left[{ }^{14} \mathrm{C}\right] 2-\mathrm{DG}$ out of the cells. These slices were co-exposed with a commercially available $\left[{ }^{14} \mathrm{C}\right]$ standard to autoradiography film for four days. After the exposure time, the autoradiograms were developed in a dark room. The autoradiograms were quantified with MCID Basic 7.0 (Imaging Research Inc., St.Catherine's, ON, Canada) image analyzer software. Relative optical densities (ROD) were transformed into levels of bound radioactivity ( $\mathrm{dpm} / \mathrm{mg}$ tissue-equivalent) after calibration using the co-exposed $\left[{ }^{14} \mathrm{C}\right]$-standard. Regions of interest were then outlined manually with reference to the stereotaxic atlas of Paxinos and Franklin 
[44]. The cortex was analyzed at three levels: frontal, the level of the striatum, and the level of the hippocampus. Other regions investigated were the cerebellum, thalamus, striatum, hippocampus, and amygdala.

For immunohistochemistry, the right brain hemisphere was fixed, paraffin-embedded and cut into $5 \mu \mathrm{m}$ coronal sections. For immunohistochemistry sections were dewaxed with xylene and rehydrated by submerging in a graded series of ethanol with decreasing concentrations. Sections to be stained for amyloid- $\beta$ underwent the following pre-treatment steps. First sections were bleached with potassium permanganate (three $\mathrm{min}$ ), rinsed in water (one min), decolorized in oxalic acid (one min), and rinsed again (one min). Thereafter, antigen retrieval was performed at room temperature by immersion in formic acid (ten min). Sections to be stained for reactive gliosis and neuronal loss underwent heat-mediated antigen retrieval by microwaving in citrate buffer ( $\mathrm{pH}$ 6, ten min). For all sections endogenous peroxidase activity was quenched by rinsing in peroxidase blocking solution (DAKO S2023, Glostrup, Denmark) five min). Sections were then incubated with the appropriate primary antibody at room temperature (60 min). For detection of amyloid- $\beta$ the primary antibody clone 4G8 (Eurogentec SIG-39200, 1/20, 000, Fremont, CA, USA) was used. Reactive gliosis was detected with anti- glial fibrillary acidic protein (GFAP) (Calbiochem IF03L, 1/500, San Diego, CA, USA) and anti-Iba-1 (Wako 019-19741, 1/500 dilution, Richmond, VA, USA) primary antibodies. Following incubation with the respective primary antibody, sections were thoroughly rinsed in wash buffer and subsequently incubated in peroxidase coupled secondary antibody (30 min) (DAKO K4001, DAKO K4002). After, sections were washed in buffer and immunodetection was performed by treatment with the chromogenic 3-3 diaminobenzidine (DAB) solution. Finally sections were counterstained with hematoxylin, dehydrated by submerging in a series of ethanol, fixed in xylene, mounted and coverslipped.

For sections stained for amyloid- $\beta$, virtual images were acquired using a Mirax Digital Slide Scanner (Carl Zeiss, Germany) and image analysis was performed using the Definiens analysis software package v1.5. For all other stainings, slides were scanned with a NanoZoomer slide scanner (Hamamatsu Photonics, Shizuoka, Japan) and analyzed with Matlab/Phaedra. In each case, regionsof-interest (ROIs) were manually delineated in accordance with Franklin and Paxinos atlas [44] and for each ROI the percentage of DAB-labeled area was calculated.

\section{Statistical analysis}

Statistical analysis was performed with GraphPad Prism v6 software.

\section{Results}

In vivo $\mu$ PET imaging

$\left[^{18}\right.$ F]FDG

VOI analysis (Fig. 1a) demonstrated a trend of reduced $\left[{ }^{18}\right.$ F]FDG uptake in APPPS1-21 mice that reached significance in the thalamus $(p=0.00068)$ and striatum $(p=0.0048)$. We additionally employed voxelwise analysis (threshold $p<0.01$, extent threshold 100 voxels) to investigate whether APPPS1-21 mice had either increased or decreased $\left[{ }^{18} \mathrm{~F}\right] \mathrm{FDG}$ uptake in comparison to age-matched WT.

Using two-sample t-tests no voxels were shown to have significantly increased uptake in APPPS1-21 (additionally at the lower threshold of $p<0.05$ ). On the other hand, significant decreases(threshold $\mathrm{p}<0.01$ ) in uptake were detected and are summarized in Fig. $2 \mathrm{a}$ as the

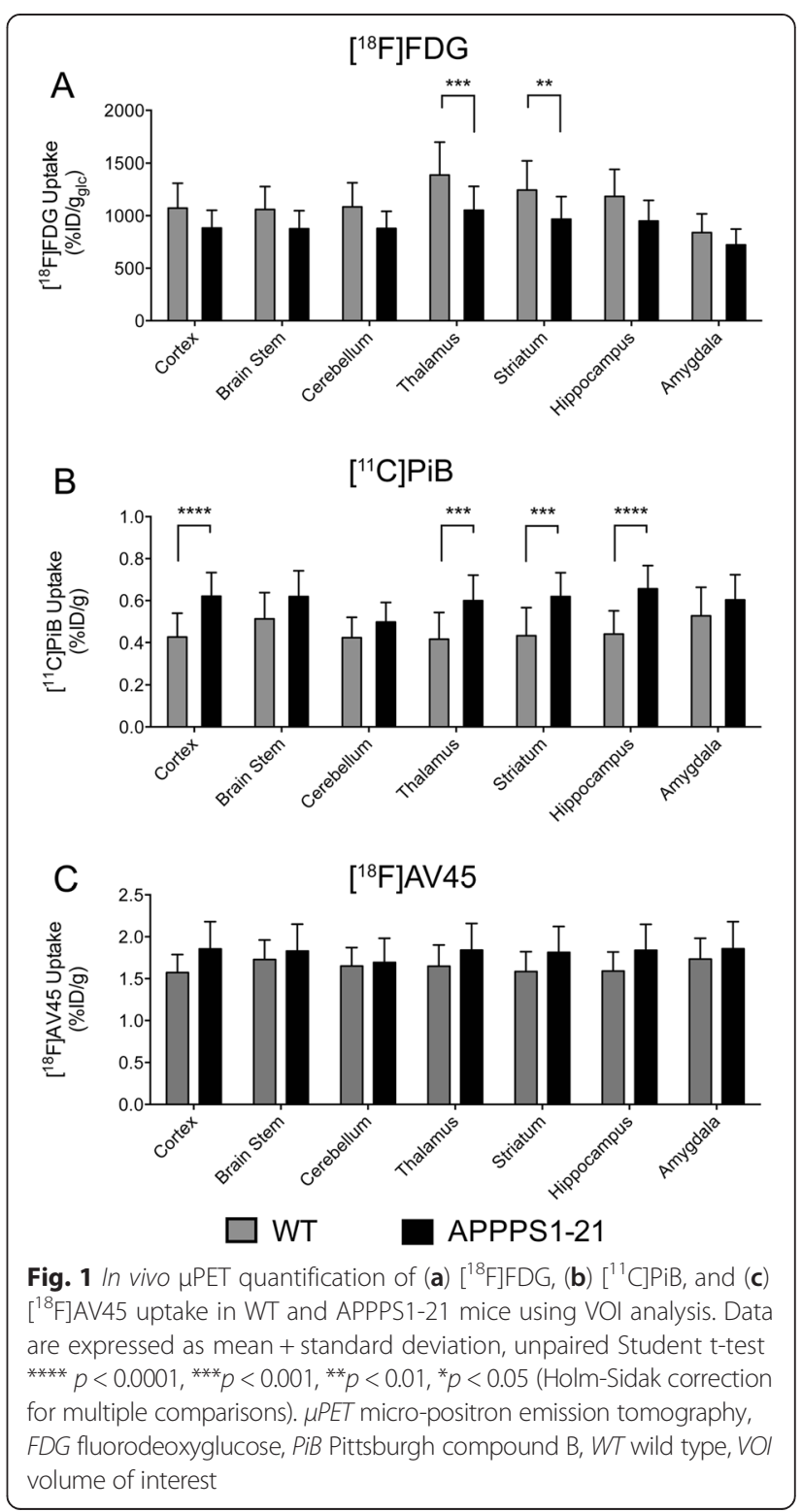



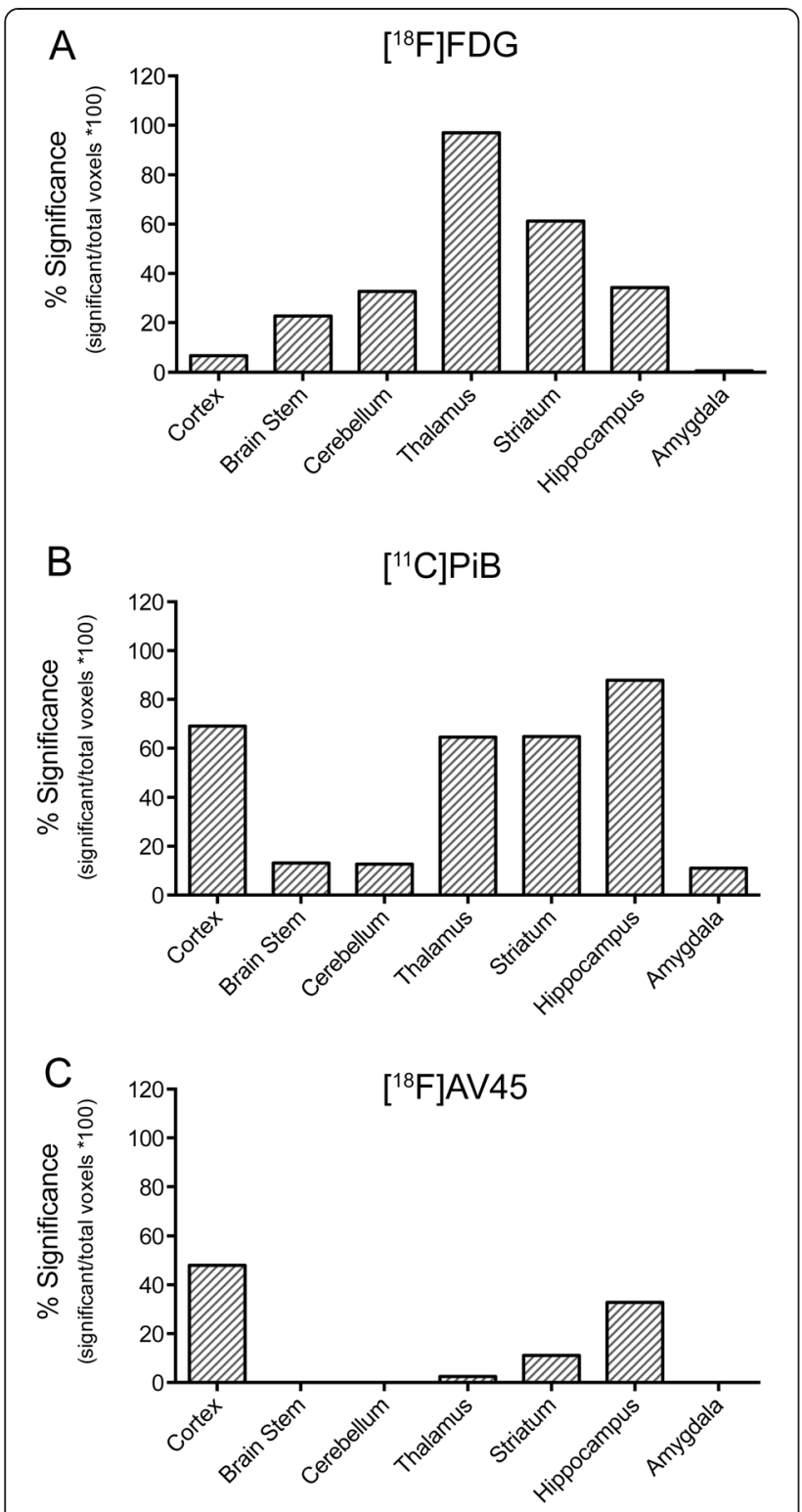

Fig. 2 In vivo analysis of glucose utilization and fibrillar amyloid- $\beta$ using voxel-wise SPM analysis. Graphs show the results from regional voxel-wise analysis of $\mu P E T$ data. Statistically significant voxels relative to the total number of voxels in a region are depicted for a $\left.{ }^{18}{ }^{18} \mathrm{~F}\right] \mathrm{FDG}$, b $\left[{ }^{11} \mathrm{C}\right] \mathrm{PiB}$, and $\mathbf{c}\left[{ }^{18} \mathrm{~F}\right] \mathrm{AV} 45$. ). SPM statistical parametric mapping, $\mu$ PET micro-positron emission tomography, FDG fluorodeoxyglucose, PiB Pittsburgh compound B

percent of significantly changed voxels within each brain region. The thalamus was the most affected with near widespread significant reductions $(96.96 \%$, maxT $=3.35)$ and was followed by the striatum in which significant decreases covered more than half of the region (61.21\%, $\max \mathrm{T}=3.29)$. The hippocampus $(34.22 \%, \max \mathrm{T}=3.13)$, cerebellum $(32.68 \%$, maxT $=3.98)$, and brain stem $(22.66 \%, \operatorname{maxT}=4.49)$ were affected to a lower extent while the cortex $(6.74 \%, \operatorname{maxT}=3.19)$ and amygdala
$(0.57 \%, \max T=2.64)$ showed minimal changes. This is visualized in Fig. 3 where the statistical T-map illustrates these regions of significantly decreased $\left[{ }^{18} \mathrm{~F}\right] \mathrm{FDG}$ uptake in APPPS1-21 mice compared to WT.

\section{$\left[{ }^{11} \mathrm{C}\right] \mathrm{PiB}$ and $\left[{ }^{18} \mathrm{~F}\right] \mathrm{AV} 45$}

VOI analysis (Fig. 1b) demonstrated increased retention of $\left[{ }^{11} \mathrm{C}\right] \mathrm{PiB}$ in APPPS1-21 mice with the cortex $(p=8.35 \mathrm{e}-005)$ and hippocampus $(p=1.54 \mathrm{e}-005)$ showing the greatest significant difference. $\left[{ }^{18} \mathrm{~F}\right] \mathrm{AV} 45$ retention was increased in APPPS1-21 mice but did not reach significance.

Additionally, $\left[{ }^{11} \mathrm{C}\right] \mathrm{PiB}$ and $\left[{ }^{18} \mathrm{~F}\right] \mathrm{AV} 45$ uptake was similarly analyzed using voxel-wise analysis and a two-sample unpaired t-test (threshold $p<0.01$, extent threshold 100 voxels). APPPS1-21 mice demonstrated a number of regions with significantly increased $\left[{ }^{11} \mathrm{C}\right] \mathrm{PiB}$ binding. These increases are summarized in Fig. 2b and illustrated in Fig. 3. The hippocampus demonstrated the most substantial changes $(87.84 \%, \operatorname{maxT}=7.15)$ followed by the cortex $(69.08 \%$, $\operatorname{maxT}=7.93)$, striatum $(64.75 \%$, $\max T=7.05)$, and thalamus $(64.57 \%, \max T=5.82)$. Modest changes ( $<15 \%)$ were observed in the brain stem, cerebellum, and amygdala. Using the same threshold value, significantly increased $\left[{ }^{18} \mathrm{~F}\right] \mathrm{AV} 45$ uptake was also demonstrated (Fig. 2c); however, in comparison to $\left[{ }^{11} \mathrm{C}\right] \mathrm{PiB}$ there were notably lower maxT values (i.e., less significance) and less widespread changes. With this tracer the cortex demonstrated the most widespread significant differences (48.01\%, $\max \mathrm{T}=4.68)$, followed by the hippocampus $(32.84 \%$, $\max \mathrm{T}=3.89)$ and striatum $(11.09 \%$, maxT $=3.59)$. Figure 3 compares the localization of significant changes for $\left[{ }^{18} \mathrm{~F}\right] \mathrm{FDG},\left[{ }^{11} \mathrm{C}\right] \mathrm{PiB}$, and $\left[{ }^{18} \mathrm{~F}\right] \mathrm{AV} 45$. While amyloid binding is predominantly in the cortex, $\left[{ }^{18} \mathrm{~F}\right] \mathrm{FDG}$ decreases are in the mid- to hind-brain regions although some overlap can be observed in the thalamus, striatum, and hippocampus.

\section{Ex- vivo validation \\ Ex-vivo $\left[{ }^{14} C\right] 2-D G$ autoradiography}

Figure 4 a shows the quantitative analysis of $\left[{ }^{14} \mathrm{C}\right] 2-\mathrm{DG}$ autoradiography. The corpus callosum was found to be metabolically stable in APPPS1-21 mice and was thus used as a reference region to normalize regional uptake values. Multiple comparisons using unpaired Student t-tests (with Holm-Sidak correction) were performed for each region to assess the differences between APPPS1-21 and WT mice. This analysis revealed that significant decreases in $\left[{ }^{14} \mathrm{C}\right] 2-\mathrm{DG}$ uptake were found in the thalamus $(p=0.00006)$, striatum $(p=0.0041)$, and hippocampus $(p=0.00006)$.

\section{Immunohistochemistry}

Brain amyloid plaque load was determined in APPPS121 mice with 4 G8 immunostaining. Plaque load was 


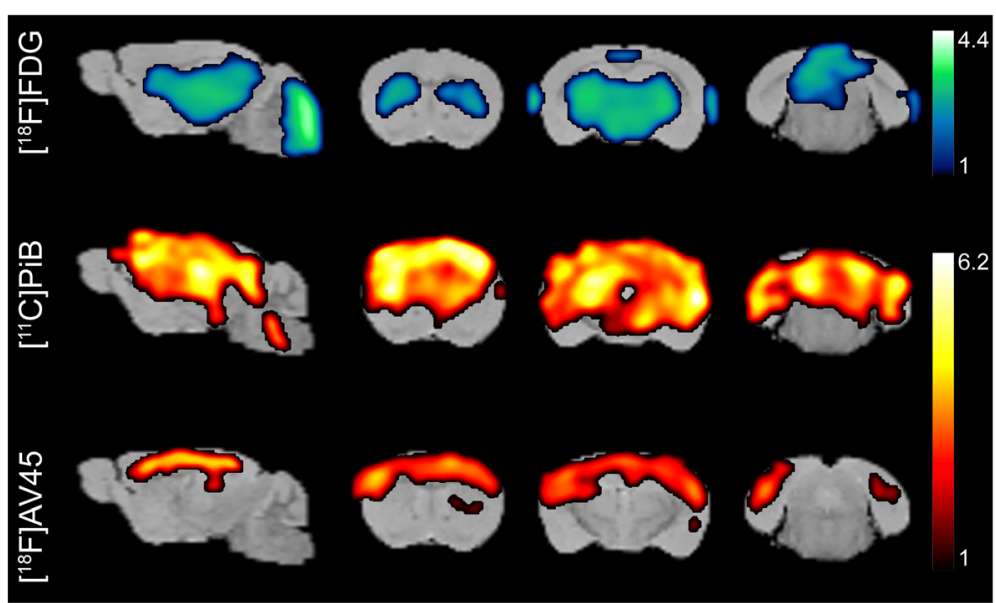

Fig. 3 Statistical parametric T-maps obtained from voxel-wise analysis of $\mu$ PET data with $\left[{ }^{18} \mathrm{~F}\right] \mathrm{FDG},\left[{ }^{11} \mathrm{C}\right] \mathrm{PiB}$ and $\left[{ }^{18} \mathrm{~F}\right] \mathrm{AV} 45$

abundant in these aged mice, with amyloid deposition highest in the frontal cortex $(7.67 \pm 0.71 \%$ marker stain) followed by the cortex at the level of the hippocampus (4.95 $\pm 0.97 \%$ marker stain), amygdala (4.12 \pm 1.47$)$ and thalamus $(3.43 \pm 0.45 \%$ marker stain). In line with its low transgene expression, minimal plaque staining was observed in the cerebellum $(0.24 \pm 0.14 \%$ marker stain) (Fig. 5c). No amyloid plaques were detected in WT mice.

Genotypic differences in inflammatory markers were investigated in the cortex, hippocampus, and thalamus by immunohistochemistry for activated microglia and astrocytes with Iba-1 (Fig. 6a-c) and GFAP, respectively (Fig. 6d-f). Multiple comparisons using unpaired Student t-tests (with Holm-Sidak correction) were performed for each region to assess the differences between APPPS1-21 and WT mice. Both GFAP and Iba-1 staining were significantly increased in APPPS1-21 mice in the regions investigated $(p<0.0001)$ (Fig. 6a and d).

\section{Correlation analysis}

To investigate the relationship between the in vivo $\mu$ PET measurements and relative ex vivo gold standards in APPPS1-21 mice we performed correlation analyses (Pearson correlation test). The absolute quantification of the $\mu \mathrm{PET}$ data in either \%ID/g $\left(\left[{ }^{11} \mathrm{C}\right] \mathrm{PiB}\right.$ and $\left.\left[{ }^{18} \mathrm{~F}\right] \mathrm{AV} 45\right)$ or $\% \mathrm{ID} / \mathrm{g}_{\text {glc }}\left(\left[{ }^{18} \mathrm{~F}\right] \mathrm{FDG}\right.$ ) derived from VOI analysis (Fig. 1) was employed in this analysis. We found that regional $\left[{ }^{18} \mathrm{~F}\right]$ FDG uptake values demonstrated a significant positive correlation to ex vivo $\left[{ }^{14} \mathrm{C}\right] 2-\mathrm{DG}$ measures in these transgenic mice $\left(\mathrm{r}=0.67, \mathrm{r}^{2}=0.45, p<0.0001\right)$ (Fig. 7a). We investigated the association between regional

\section{WT $\square$ APPPS1-21}
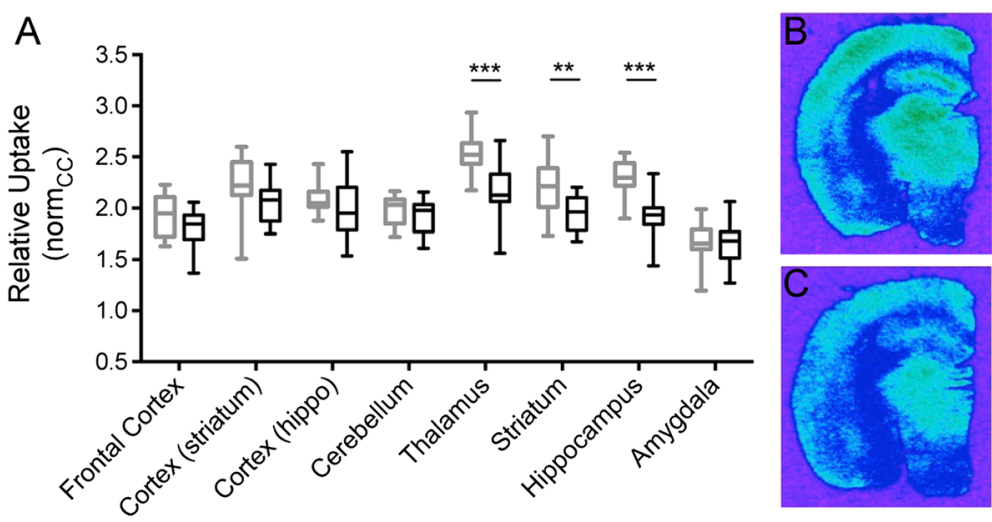

Fig. 4 Ex vivo measures of glucose utilization with $\left[{ }^{14} \mathrm{C}\right] 2-\mathrm{DG}$ autoradiography in aged APPPS1-21 and WT mice. a Box-plots show the normalized regional $\left[{ }^{14} C\right] 2-D G$ uptake values for WT and APPPS1-21 mice in different brain regions. Unpaired Student t-test, ${ }^{* *} p<0.01,{ }^{* * *} p<0.001$. Representative images are shown for (b) a WT and (c) a APPPS1-21 animal. 2-DG 2-deoxy-D-glucose, WT wild type 

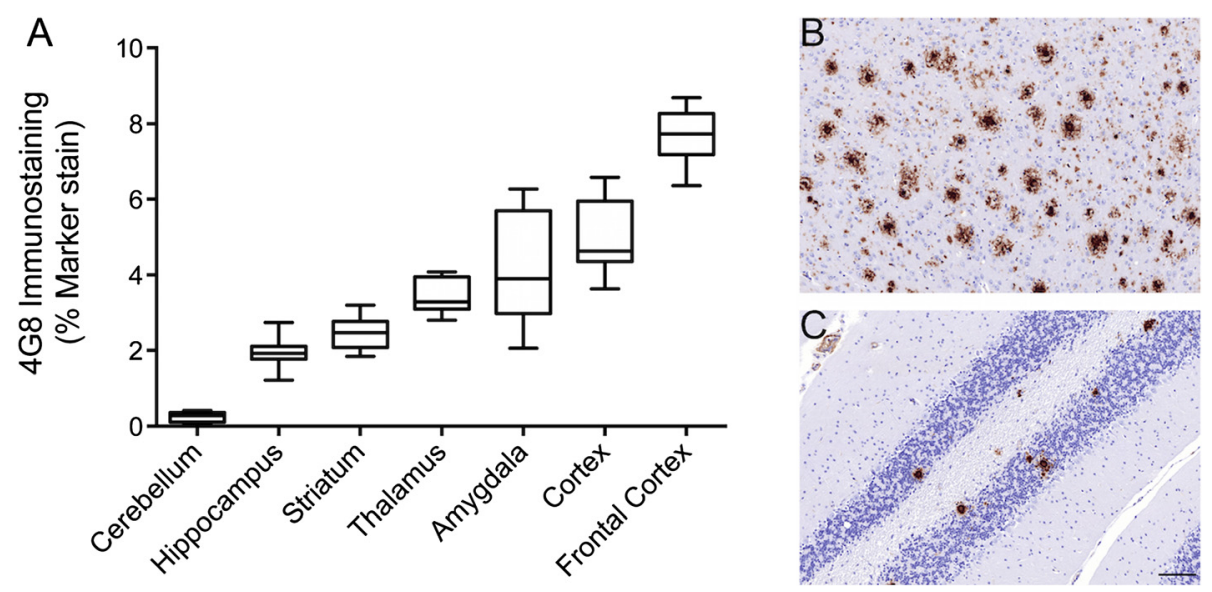

Fig. 5 Ex vivo immunohistochemistry for amyloid- $\beta$ with $4 \mathrm{G} 8$ immunostaining in APPPS1-21 mice. a Data are presented as the max and min \pm standard deviation. Representative images from (b) the frontal cortex and (c) the cerebellum of an APPPS1-21 mouse (Scale bar = $100 \mu \mathrm{m}$ )

\section{WT $\square$ APPPS1-21}
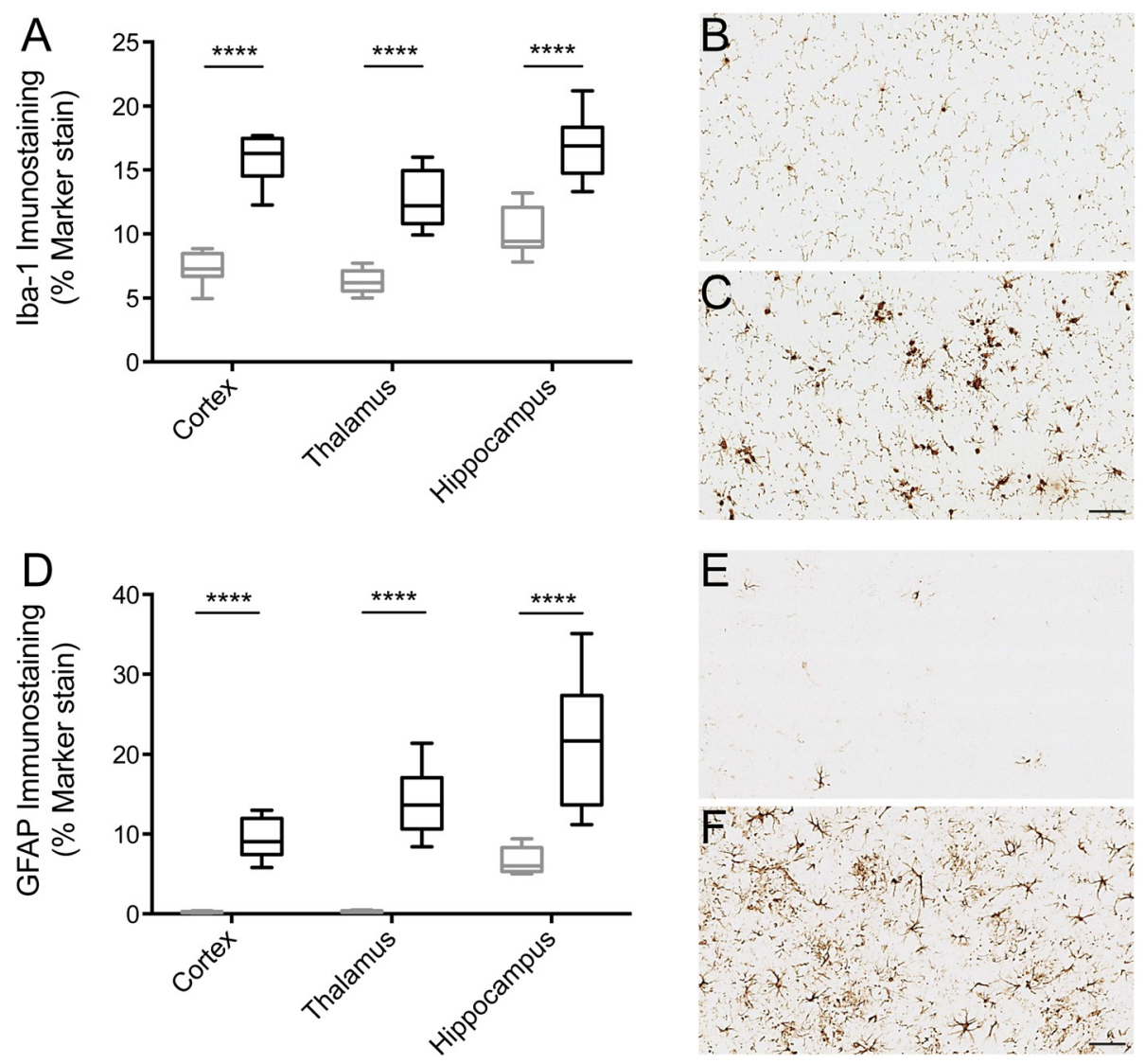

Fig. 6 Ex vivo immunohistochemistry for the inflammatory markers GFAP and Iba-1 in APPPS1-21 and WT mice. a and (d) data are presented as the max and $\min \pm$ standard deviation. Unpaired Student t-test ${ }^{* * *} p<0.0001$. Representative images from the cortex of WT (b) and (e), and APPPS1-21 $\mathbf{c}$ and $\mathbf{f}$ mice (Scale bar =50 $\mu \mathrm{m}$ ). GFAP glial fibrillary acidic protein, lba-1 ionized calcium-binding adaptor molecule 1, WT wild type 

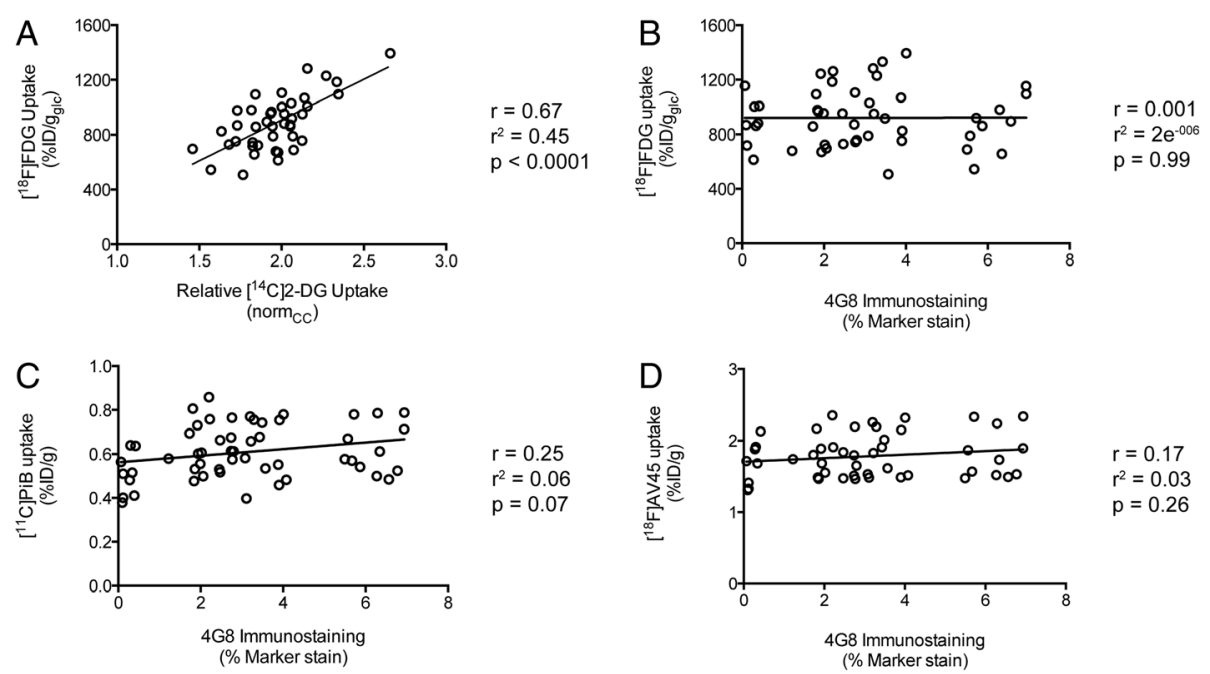

Fig. 7 Correlation analyses between in vivo $\mu$ PET data and ex vivo measures of amyloid burden and glucose utilization. a Graph depicting $\left[{ }^{18} \mathrm{~F}\right] \mathrm{FDG}$ and $\left[{ }^{14} \mathrm{C}\right] 2-\mathrm{DG}$ quantification of brain glucose utilization. $\mathbf{b}$ Graph of $\left[{ }^{18} \mathrm{~F}\right] \mathrm{FDG}$ uptake versus amyloid burden. $\mathbf{c}$ Graph of $\left[{ }^{11} \mathrm{C}\right] \mathrm{PiB}$ and $4 \mathrm{G} 8$ quantification of amyloid burden. $\mathbf{d}$ Graph of $\left[{ }^{18} \mathrm{~F}\right] \mathrm{AV} 45$ and $4 \mathrm{G} 8$ quantification of amyloid burden. Each dot represents a regional value from an individual animal (cortex, striatum, amygdala, hippocampus, thalamus, and cerebellum). Only APPPS1-21 mice were included in this analysis. HPET micro-positron emission tomography, FDG fluorodeoxyglucose, 2-DG 2-deoxy-D-glucose, PiB Pittsburgh compound B

$\left[{ }^{18}\right.$ F]FDG uptake and amyloid- $\beta$ deposition but found that these measures were not correlated $\left(r=0.01, r^{2}=2 \mathrm{e}\right.$ ${ }^{-006}, p=0.99$ ) (Fig. 7b). In contrast, in vivo $\left[{ }^{11} \mathrm{C}\right] \mathrm{PiB}$ and $\left[{ }^{18} \mathrm{~F}\right] \mathrm{AV} 45$ binding did not correlate strongly to ex vivo 4G8 immunostaining for amyloid- $\beta$ in APPPS1-21 mice $\left(\mathrm{r}=0.25, \mathrm{r}^{2}=0.06, p=0.07\right.$ and $\mathrm{r}=0.17, \mathrm{r}^{2}=0.03, p=0.26$ respectively) (Fig. $7 \mathrm{c}$ and $\mathrm{d}$ ).

\section{Discussion}

Due to its non-invasive nature, $\mu \mathrm{PET}$ imaging is an attractive modality for preclinical investigation that allows for the visualization of multiple neuropathological biomarkers. $\left[{ }^{18} \mathrm{~F}\right] \mathrm{FDG}$ detected significant decreases in cerebral metabolism in APPPS1-21 mice and showed a high congruency to ex vivo measures of $\left[{ }^{14} \mathrm{C}\right] 2-\mathrm{DG}$. Both $\left[{ }^{11} \mathrm{C}\right] \mathrm{PiB}$ and $\left[{ }^{18} \mathrm{~F}\right] \mathrm{AV} 45$ demonstrated significant uptake in APPPS1-21 mice but showed poor sensitivity when compared to ex vivo amyloid quantification. The detected reductions in $\left[{ }^{18} \mathrm{~F}\right] \mathrm{FDG}$ did not correlate to regions of highest amyloid- $\beta$ burden.

A number of animal models of AD have been investigated with in vivo $\left[{ }^{18} \mathrm{~F}\right] \mathrm{FDG}$ imaging but no consensus has been reached on its utility. On the whole, most investigations of amyloidosis-only models have revealed unchanged [24, 25] or increased uptake [26-28], counter to the clinical phenotype. These findings were interpreted as a fundamental limitation of animal models and, additionally, a limit in the sensitivity of $\mu$ PET. However, more recently, widespread significant decreases in $\left[{ }^{18} \mathrm{~F}\right] \mathrm{FDG}$ in the $5 \times$ FAD model have been reported [31] and we have detected significant regional decreases in the double transgenic TASTPM model [32, 33]. It is possible that normal, hypometabolism and hypermetabolism can be observed at different disease stages in animal models depending on disease severity that depends on both the mutations and the age at imaging. Other likely contributors to the controversy are methodological differences, especially in relation to analysis. Normalization of regional uptake values to a reference region is common but may yield inaccurate results if such regions are compromised by disease [45]. In comparison the use of voxelwise analysis provides more sensitivity to detect changes and allows for multiple hypothesis testing (i.e., hyper or hypo) and should thus be routinely implemented in studies of cerebral glucose metabolism One limitation of $\mu \mathrm{PET}$ imaging is the necessitation to anesthetize the animal and in the case of $\left[{ }^{18} \mathrm{~F}\right]$ FDG studies this results in substantially reduced brain uptake of the tracer [46]. The $\left[{ }^{14} \mathrm{C}\right] 2-\mathrm{DG}$ protocol is, however, performed without the confounding effects of anesthesia and, thus, the correlation between in vivo and ex vivo results strongly suggests that the $\left[{ }^{18} \mathrm{~F}\right] \mathrm{FDG}$ findings are reliable. With the aforementioned methodological considerations we have now demonstrated $\left[{ }^{18} \mathrm{~F}\right] \mathrm{FDG}$ reductions in two transgenic models of AD and aim to further extend our findings in other models for multiple stages of pathology.

While this is the first investigation of cerebral glucose utilization in the APPPS1-21 model, these mice have been previously characterized with amyloid imaging $[15,16,38]$. Significant differences between WT and APPPS1-21 mice in the cortex have been detected at five months with $\left[{ }^{18} \mathrm{~F}\right] \mathrm{AV} 45[16]$ and at 8.4 months with $\left[{ }^{11} \mathrm{C}\right] \mathrm{PiB}$ 
[15]. In this study, both $\left[{ }^{11} \mathrm{C}\right] \mathrm{PiB}$ and $\left[{ }^{18} \mathrm{~F}\right] \mathrm{AV} 45$ demonstrated increased retention in APPPS1-21 mice with $\left[{ }^{11} \mathrm{C}\right] \mathrm{PiB}$ showing a higher discriminative power. $\left[{ }^{11} \mathrm{C}\right] \mathrm{PiB}$ has previously been shown to have a greater dynamic range than most fluorinated alternatives [38, 47]. The reduced contrast obtained with tracers, such as $\left[{ }^{18} \mathrm{~F}\right] \mathrm{AV} 45$ and $\left[{ }^{18} \mathrm{~F}\right]$ florbetaben, is due to a higher proportion of nonspecific binding resulting from a combination of white matter retention and the uptake of brain penetrant radiometabolites. With relevance to the current findings, Choi et al. described two main brain penetrant radiometabolites of $\left[{ }^{18} \mathrm{~F}\right] \mathrm{AV} 45$ [48]. The non-specific uptake of these metabolites most likely accounts for the poor performance of $\left[{ }^{18} \mathrm{~F}\right] \mathrm{AV} 45$ when compared to $\left[{ }^{11} \mathrm{C}\right] \mathrm{PiB}$. A previous preclinical study found a similarly low contrast whereby only a $14.5 \%$ difference between WT and transgenic mice (5XFAD) was observed with $\left[{ }^{18} \mathrm{~F}\right]$-AV45 in comparison to a $21 \%$ difference obtained with $\left[{ }^{11} \mathrm{C}\right]-\mathrm{PiB}$ in the same mouse cohort [27]. While we detected amyloid- $\beta$ in vivo with $\left[{ }^{11} \mathrm{C}\right] \mathrm{PiB}$ and $\left[{ }^{18} \mathrm{~F}\right] \mathrm{AV} 45$ binding, we observed discrepancies with ex vivo determinants of amyloid- $\beta$ load for both these tracers. Voxel-wise analysis of $\left[{ }^{11} \mathrm{C}\right] \mathrm{PiB}$ binding found the hippocampus to have the most widespread increases whereas immunohistochemistry showed this region had lower amyloid- $\beta$ deposition than in the thalamus, cortex, and striatum. We have previously described poor correlation between in vivo binding of amyloid tracers and ex vivo measures of amyloid with $\left[{ }^{18} \mathrm{~F}\right] \mathrm{AV} 45$ [33], $\left[{ }^{18} \mathrm{~F}\right]$ florbetaben, and $\left[{ }^{11} \mathrm{C}\right] \mathrm{PiB}$ [38]. The accuracy of in vivo detection could be improved by partial volume corrections [49] but the poor correlation is also indicative of the high non-specific binding inherent to these amyloid tracers.

Although aged APPPS1-21 mice demonstrated significant reductions in cerebral metabolism, the regions affected were not congruent with those of human AD. In $\mathrm{AD}$, patients typically show reduced $\left[{ }^{18} \mathrm{~F}\right] \mathrm{FDG}$ uptake in the precuneus, posterior cingulate, and temporal and parietal cortex. With increasing disease severity hypometabolism spreads to frontal association cortices but metabolism remains largely preserved in the striatum, thalamus, visual and sensorimotor cortices, and the cerebellum and brain stem throughout disease progression [2]. In aged APPPS1-21 mice, minimal reductions were observed in the cortex whereas the most significant reductions were in the thalamus and striatum. Moreover, typically amyloid-free regions in these mice, such as the brain stem and cerebellum, also demonstrated significant reductions. While some previous ex vivo autoradiography studies with $\left[{ }^{18} \mathrm{~F}\right] \mathrm{FDG}$ and $\left[{ }^{14} \mathrm{C}\right] 2$-DG found significant decreases in $\mathrm{AD}$ relevant structures, such as the retrospinal and/or cingulate cortex $[19,20]$, the overall pattern of $\left[{ }^{18} \mathrm{~F}\right] \mathrm{FDG} /\left[{ }^{14} \mathrm{C}\right] 2-\mathrm{DG}$ was incongruent to human AD. These incongruences are perhaps not surprising given the inherent differences between animal models and human AD. The majority of cerebral amyloidosis models do not develop overt neuronal death [9] which is a prominent hallmark of human $\mathrm{AD}$ and is thought to largely underlie decreases in $\left[{ }^{18} \mathrm{~F}\right] \mathrm{FDG}$ uptake. While amyloid deposition initiates at six to eight weeks of age, only modest neuronal loss is observed beginning at eight months in APPPS1-21 mice [36]. Accordingly, these animals showed no brain atrophy when investigated with MRI voxel-based analysis [50]. The neuronal loss that was observed was found in the dentate gyrus and CA1 layers of the hippocampus $[36,51]$. Atrophy and neuronal loss were notably absent in the cortex which could explain the lack of $\left[{ }^{18} \mathrm{~F}\right]$ FDG decreases in this region $[50,51]$. Further investigations into the biological underpinnings of $\left[{ }^{18} \mathrm{~F}\right]$ FDG decreases in this model are required. Of interest, early loss of dendritic spines has been reported in APPPS1-21 mice and could thus represent a relevant target for future studies [34].

Despite some overlapping pathology, decreases in $\left[{ }^{18} \mathrm{~F}\right]$ FDG uptake do not correlate well with increases in amyloid retention $[52,53]$. Inflammation in high plaquebearing regions has been postulated as a factor for the lack of correlation between amyloid tracer retention and reductions in $\left[{ }^{18} \mathrm{~F}\right] \mathrm{FDG}$ [54]. As glial cells also use glucose as an energy source it is proposed that increased inflammation in proximity to plaques may mask decreased neuronal activity. Indeed, in a study of aged monkeys $\left[{ }^{18} \mathrm{~F}\right] \mathrm{FDG}$ uptake positively correlated with increased binding of the microglial marker $\left[{ }^{11} \mathrm{C}\right] \mathrm{DPA}-713$ rather than with $\left[{ }^{11} \mathrm{C}\right] \mathrm{PiB}$ binding [54]. In APPPS1-21 mice, activated microglia and astrocytes appear in tandem with the onset of amyloid deposition and increase in number with disease progression [36]. In line with these observations, we demonstrated significant increases in inflammatory markers for astrocytes (GFAP) and microglia (Iba-1) in the thalamus, cortex and hippocampus of APPPS1-21 mice. Despite this robust neuroinflammation, APPPS1-21 mice still demonstrate significant $\left[{ }^{18} \mathrm{~F}\right] \mathrm{FDG}$ decreases. While this does not discount the involvement of inflammation in the $\left[{ }^{18} \mathrm{~F}\right] \mathrm{FDG}$ signal, taken together we find it insufficient to fully account for the poor correlation. An alternative hypothesis for this dissociation is network degeneration which proposes that the disease propagates along neuronal networks [55]. In this case amyloid deposition in addition to causing local synaptic dysfunction would also induce dysfunction in functionally connected regions which may themselves be amyloid-free. This theory is supported by recent clinical evidence demonstrating that worsening amyloidosis is correlated to worsening hypometabolism in both local and functionally related regions [56]. It should, however, be remembered that imaging data relates to measures of fibrillar amyloid- $\beta$ and thus does not provide information on the relationship 
between soluble amyloid- $\beta$ which is especially neurotoxic and likely influences neuronal dysfunction [57]. Interestingly, decreases in functional connectivity have been reported in APPPS1-21 mice with resting state fMRI [58].

We only investigated pathology in our animal model at a single time point. Additionally we choose this old age time point as we expected substantial pathological burden at this stage of disease. Therefore, to fully assess the utility of $\left[{ }^{18} \mathrm{~F}\right] \mathrm{FDG}$ and to delineate the temporal relationship between amyloid deposition and neuronal dysfunction a longitudinal study should be performed. Furthermore, in this study we aimed to primarily demonstrate $\left[{ }^{18} \mathrm{~F}\right] \mathrm{FDG}$ as a useful tracer in preclinical investigations. Future investigations should focus on finding the underlying mechanisms of these $\left[{ }^{18} \mathrm{~F}\right] \mathrm{FDG}$ alterations and their relationship to neurodegeneration as has been recently described in a Tau transgenic model [59].

\section{Conclusions}

Our study provides support for the use of $\left[{ }^{18} \mathrm{~F}\right] \mathrm{FDG}$ as an in vivo technique to investigate abnormal cerebral glucose utilization in transgenic models of AD. Our findings suggest that the combined use of in vivo amyloid and $\left[{ }^{18} \mathrm{~F}\right]$ FDG $\mu$ PET imaging will aid in understanding the relationship between amyloid and neuronal dysfunction.

\begin{abstract}
Abbreviations
$\% \mid D / g$ : Percent injected dose per gram; \%ID/g gram glucose corrected; 2-DG: 2-Deoxy-D-glucose; AD: Alzheimer's Disease; ANOVA: Analysis of variance; APP: Amyloid precursor protein; CT: Computed tomography; DAB: 3,3-Diaminobenzidine; dpm: Disintegrations per minute; FDG: Fluorodeoxyglucose; FORE: Fourier rebinning; FWHM: Full width at half maximum; GFAP: Glial fibrillary acidic protein; Iba-1: Ionized calcium-binding adaptor molecule 1; keV: Kiloelectron-volt; maxT: Maximal T-value; MBq: Megabequeral; MR: Magnetic resonance; MRI: Magnetic resonance imaging; NeuN: Neuronal nuclei; nsec: Nanosecond; OSEM2D: Two-dimensional ordered subset estimation maximization; PET: Positron emission tomography; PiB: Pittsburgh compound B; PS1: Presenilin 1; ROD: Relative optical density; ROI: Region of interest; SPM: Statistical parametric mapping; SSS: Single scatter simulation; UA: Microampere; VOI: Volume of interest; WT: Wild type; HPET: Micro-positron emission tomography.
\end{abstract}

\section{Competing interests}

$X L, M S, C W, A B$, and JBK are employed by Janssen Pharmaceutica NV. All the remaining authors declare that they have no competing interests.

\section{Authors' contributions}

AM generated the imaging data, performed the image processing and data interpretation in addition to drafting and revising the manuscript and executing the experimental design. CW, AB, and JBK processed tissue for immunohistochemistry and autoradiography in addition to data analysis and interpretation and providing critical commentary during manuscript drafting and revision. XL, MS, StSt, and SiS conceived the study, coordinated the experimental design and contributed to the writing and proofreading of the manuscript. All authors read and approved the final manuscript.

\section{Acknowledgements}

This work was funded by Antwerp University and its University Hospital, Antwerp, Belgium through an associate professor position for St.S and a full professor position for Si.St. AMW is supported through a scholarship from the Agency of Innovation by Science and Technology in Flanders (IWT). The authors are thankful to Philippe Joye (Molecular Imaging Center Antwerp) for support with in vivo experiments and to Hilde Vermeirsch (HistoGeneX) for help with ex vivo tissue processing.

\section{Author details}

'Molecular Imaging Center Antwerp, University of Antwerp, Campus Drie Eiken - UC, Universiteitsplein 1, 2610, Wilrijk, Antwerp, Belgium.

${ }^{2}$ Neuroscience Research \& Development, Janssen Pharmaceutica NV, Beerse, Belgium. ${ }^{3}$ Nuclear Medicine Department, University Hospital Antwerp, Antwerp, Belgium.

Received: 22 July 2015 Accepted: 21 October 2015

Published online: 15 December 2015

\section{References}

1. Mosconi L. Brain glucose metabolism in the early and specific diagnosis of Alzheimer's disease. FDG-PET studies in MCI and AD. Eur J Nucl Med Mol Imaging. 2005;32:486-510.

2. Herholz K, Salmon E, Perani D, Baron JC, Holthoff V, Frolich L, et al. Discrimination between Alzheimer dementia and controls by automated analysis of multicenter FDG PET. Neurolmage. 2002;17:302-16.

3. Kogure D, Matsuda H, Ohnishi T, Asada T, Uno M, Kunihiro T, et al. Longitudinal evaluation of early Alzheimer's disease using brain perfusion SPECT. J Nucl Med. 2000;41:1155-62.

4. Edison P, Archer HA, Gerhard A, Hinz R, Pavese N, Turkheimer FE, et al. Microglia, amyloid, and cognition in Alzheimer's disease: An [11C](R)PK11195-PET and [11C]PIB-PET study. Neurobiol Dis. 2008;32:412-9.

5. Okello A, Edison P, Archer HA, Turkheimer FE, Kennedy J, Bullock R, et al. Microglial activation and amyloid deposition in mild cognitive impairment a PET study. Neurology. 2009;72:56-62.

6. Klunk WE, Engler $H$, Nordberg A, Wang Y. Imaging brain amyloid in Alzheimer's disease with Pittsburgh Compound-B. Ann Neurol. 2004:55:306-19.

7. Xia CF, Arteaga J, Chen G, Gangadharmath U, Gomez LF, Kasi D, et al. [18 F]T807, a novel tau positron emission tomography imaging agent for Alzheimer's disease. Alzheimers Dement. 2013;9:666-76.

8. Johnson KA, Fox NC, Sperling RA, Klunk WE. Brain imaging in Alzheimer disease. Cold Spring Harb Perspect Med. 2012;2:a006213.

9. Götz J, Ittner LM. Animal models of Alzheimer's disease and frontotemporal dementia. Nat Rev Neurosci. 2008;9:532-44.

10. Klunk WE, Lopresti BJ, Ikonomovic MD, Lefterov IM, Koldamova RP,

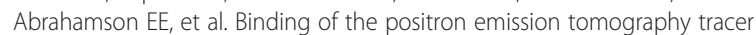
Pittsburgh compound-B reflects the amount of amyloid-beta in Alzheimer's disease brain but not in transgenic mouse brain. J Neurosci. 2005;25:10598-606

11. Maeda J, Ji B, Irie T, Tomiyama T, Maruyama M, Okauchi T, et al. Longitudinal, quantitative assessment of amyloid, neuroinflammation, and anti-amyloid treatment in a living mouse model of Alzheimer's disease enabled by positron emission tomography. J Neurosci. 2007;27:10957-68.

12. Manook A, Yousefi BH, Willuweit A, Platzer S, Reder S. Small-animal PET imaging of amyloid-beta plaques with [11C] PiB and its multi-modal validation in an APP/PS1 mouse model of Alzheimer's disease. PLoS One. 2012; $7: \mathrm{e} 31310$

13. Rominger A, Brendel M, Burgold S, Keppler K, Baumann K, Xiong G, et al. Longitudinal assessment of cerebral $\beta$-amyloid deposition in mice overexpressing Swedish mutant $\beta$-amyloid precursor protein using 18 F-florbetaben PET. J Nucl Med. 2013;54:1127-34.

14. Snellman A, Lopez-Picon FR, Rokka J, Salmona M, Forloni G, Scheinin M, et al. Longitudinal amyloid imaging in mouse brain with 11C-PIB: comparison of APP23, Tg2576, and APPswe-PS1dE9 mouse models of Alzheimer disease. J Nucl Med. 2013;54:1434-41.

15. Maier FC, Wehrl HF, Schmid AM, Mannheim JG, Wiehr S, Lerdkrai C, et al. Longitudinal PET-MRI reveals $\beta$-amyloid deposition and rCBF dynamics and connects vascular amyloidosis to quantitative loss of perfusion. Nat Med. 2014;20:1485-92.

16. Poisnel G, Dhilly M, Moustié O, Delamare J, Abbas A, Guilloteau D, et al. PET imaging with [18 F]AV-45 in an APP/PS1-21 murine model of amyloid plaque deposition. Neurobiol Aging. 2012;33:2561-71.

17. Rodriguez-Vieitez E, Ni R, Gulyás B, Toth M, Häggkvist J, Halldin C, et al. Astrocytosis precedes amyloid plaque deposition in Alzheimer APPswe transgenic mouse brain: a correlative positron emission tomography and in vitro imaging study. Eur J Nucl Med Mol Imaging. 2015;42:1119-32. 
18. Brendel M, Jaworska A, Herms J, Trambauer J, Rötzer C, Gildehaus FJ, et al. Amyloid-PET predicts inhibition of de novo plaque formation upon chronic $\gamma$-secretase modulator treatment. Mol Psychiatry. 2015;20:117987.

19. Valla J, Schneider L, Reiman EM. Age- and transgene-related changes in regional cerebral metabolism in PSAPP mice. Brain Res. 2006;1116:194-200.

20. Valla J, Gonzalez-Lima F, Reiman EM. FDG autoradiography reveals developmental and pathological effects of mutant amyloid in PDAPP transgenic mice. Int J Dev Biol. 2008;26:253-8.

21. Reiman EM, Uecker A, Gonzalez-Lima F, Minear D, Chen K, Callaway NL, et al. Tracking Alzheimer's disease in transgenic mice using fluorodeoxyglucose autoradiography. NeuroReport. 2000;11:987-91.

22. Dodart JC, Mathis C, Bales KR, Paul SM, Ungerer A. Early regional cerebral glucose hypometabolism in transgenic mice overexpressing the V717F -amyloid precursor protein. Neurosci Lett. 1999;277:49-52

23. Dubois A, Hérard AS, Delatour B, Hantraye P, Bonvento G, Dhenain M, et al. Detection by voxel-wise statistical analysis of significant changes in regional cerebral glucose uptake in an APP/PS1 transgenic mouse model of Alzheimer's disease. Neurolmage. 2010;51:586-98.

24. Rapic S, Backes H, Viel T, Kummer MP, Monfared P, Neumaier B, et al. Imaging microglial activation and glucose consumption in a mouse model of Alzheimer's disease. Neurobiol Aging. 2012;34:351-4.

25. Kuntner C, Kesner AL, Bauer M, Kremslehner R, Wanek T, Mandler M, et al. Limitations of small animal PET imaging with [18 F]FDDNP and FDG for quantitative studies in a transgenic mouse model of Alzheimer's disease. Mol Imaging Biol. 2009;11:236-40.

26. Poisnel G, Hérard AS, EL Tannir El Tayara N, Bourrin E, Volk A, Kober F, et al. Increased regional cerebral glucose uptake in an APP/PS1 model of Alzheimer's disease. Neurobiol Aging. 2012;33:1995-2005.

27. Rojas S, Herance JR, Gispert JD, Abad S, Torrent É, Jiménez X, et al. In vivo evaluation of amyloid deposition and brain glucose metabolism of 5XFAD mice using positron emission tomography. Neurobiol Aging. 2013;34:1790-8

28. Luo F, Rustay NR, Ebert U, Hradil VP, Cole TB, Llano DA, et al. Characterization of 7- and 19-month-old Tg2576 mice using multimodal in vivo imaging: limitations as a translatable model of Alzheimer's disease. Neurobiol Aging. 2012;33:933-44.

29. Valla J. Effects of image resolution on autoradiographic measurements of posterior cingulate activity in PDAPP mice: implications for functional brain imaging studies of transgenic mouse models of Alzheimer's disease. Neurolmage. 2002;16:1-6.

30. Welch A, Mingarelli M, Riedel G, Platt B. Mapping changes in mouse brain metabolism with PET/CT. J Nucl Med. 2013;54:1946-53.

31. Macdonald IR, Debay DR, Reid GA, O'Leary TP, Jollymore CT, Mawko G, et al. Early detection of cerebral glucose uptake changes in the 5XFAD mouse. Curr Alzheimer Res. 2014;11:450-60

32. Kelley J, Wintmolders C, Bottelbergs A, Waldron AM, Wyffels L, Czech C, et al. Investigations of brain glucose utilization in three transgenic mouse strains that develop neuropathological features of Alzheimer's disease. Alzheimer's Dement. 2013;9:P329.

33. Waldron A, Wyffels L, Verhaeghe J, Bottelbergs A, Richardson J, Kelley J, et al. Quantitative muPET imaging of cerebral glucose metabolism and amyloidosis in the TASTPM double transgenic mouse model of Alzheimer's disease. Curr Alzheimer Res. 2015;12:694-703.

34. Bittner T, Burgold S, Dorostkar MM, Fuhrmann $M$, Wegenast-Braun BM, Schmidt B, et al. Amyloid plaque formation precedes dendritic spine loss. Acta Neuropathol. 2012;124:797-807.

35. Gengler S, Hamilton A, Hölscher C. Synaptic plasticity in the hippocampus of a APP/PS1 mouse model of Alzheimer's disease is impaired in old but not young mice. PLoS One. 2010;5:e9764.

36. Radde R, Bolmont T, Kaeser SA, Coomaraswamy J, Lindau D, Stoltze L, et al. AB42-driven cerebral amyloidosis in transgenic mice reveals early and robust pathology. EMBO Rep. 2006;7:940-6.

37. Serneels L, Van Biervliet J, Craessaerts K, Dejaegere T, Horre K, Van Houtvin $T$, et al. gamma-Secretase heterogeneity in the Aph1 subunit: relevance for Alzheimer's disease. Science. 2009;324:639-42.

38. Waldron AM, Verhaeghe J, Wyffels L, Schmidt M, Langlois $X$, Van der Linden $A$, et al. Preclinical comparison of the amyloid- $\beta$ radioligands [(11)C]Pittsburgh compound B and ] (18)F]florbetaben in aged APPPS1-21 and BRI1-42 mouse models of cerebral amyloidosis. Mol Imaging Biol. 2015;17:688-96. doi:10.1007/s11307-015-0833-9.
39. Yao CH, Lin WL, Weng CC, Hsiao IT, Ting YS, Yen TC, et al. GMP-compliant automated synthesis of [(18)F]AV-45 (Florbetapir F 18) for imaging beta-amyloid plaques in human brain. Appl Radiat Isot. 2010;68:2293-7.

40. Hudson HM, Larkin RS. Accelerated image reconstruction using ordered subsets of projection data. IEEE Trans Med Imaging. 1993;13:601-9.

41. Defrise M, Kinahan PE, Townsend DW, Michel C, Sibomana M, Newport DF Exact and approximate rebinning algorithms for 3-D PET data. IEEE Trans Med Imaging. 1997;16:145-58.

42. Watson CC. New, faster, image-based scatter correction for 3D PET. IEEE Trans Nucl Sci. 2000;47:1587-94

43. Mirrione MM, Schiffer WK, Fowler JS, Alexoff DL, Dewey SL, Tsirka SE. A novel approach for imaging brain-behavior relationships in mice reveals unexpected metabolic patterns during seizures in the absence of tissue plasminogen activator. Neurolmage. 2007;38:34-42

44. Franklin KB, Paxinos G. Mouse brain in stereotaxic coordinates. Waltham: Academic Press; 1997.

45. Gründer G. "Absolute" or 'relative': choosing the right outcome measure in neuroimaging. Neurolmage. 2009;45:258-9.

46. Matsumura A, Mizokawa S, Tanaka M, Wada Y, Nozaki S, Nakamura F, et al. Assessment of microPET performance in analyzing the rat brain under different types of anesthesia: comparison between quantitative data obtained with microPET and ex vivo autoradiography. Neurolmage. 2003;20:2040-50

47. Landau SM, Breault $C$, Joshi AD, Pontecorvo M, Mathis CA, Jagust WJ, et al. Amyloid- $\beta$ imaging with Pittsburgh compound $B$ and florbetapir: comparing radiotracers and quantification methods. J Nucl Med. 2012;54:70-7.

48. Choi SR, Golding G, Zhuang Z, Zhang W, Lim N, Hefti F, et al. Preclinical properties of 18 F-AV-45: a PET agent for Abeta plaques in the brain. J Nucl Med. 2009;50:1887-94.

49. Brendel M, Delker A, Rötzer C, Böning G, Carlsen J, Cyran C, et al. Impact of partial volume effect correction on cerebral $\beta$-amyloid imaging in APP-Swe mice using [(18)F]-florbetaben PET. Neurolmage. 2014;84:843-53.

50. Teipel SJ, Kaza E, Hadlich S, Bauer A, Brüning T, Plath AS, et al. Automated detection of amyloid- $\beta$-related cortical and subcortical signal changes in a transgenic model of Alzheimer's disease using high-field MRI. J Alzheimers Dis. 2011;23:221-37.

51. Rupp NJ, Wegenast-Braun BM, Radde R, Calhoun ME, Jucker M. Early onset amyloid lesions lead to severe neuritic abnormalities and local, but not global neuron loss in APPPS1 transgenic mice. Neurobiol Aging. 2011;32:2324. e1-6.

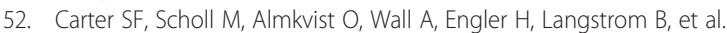
Evidence for astrocytosis in prodromal Alzheimer disease provided by $11 \mathrm{C}$ deuterium-L-deprenyl: a multitracer PET paradigm combining 11C Pittsburgh compound B and 18 F-FDG. J Nucl Med. 2012:53:37-46.

53. Kadir A, Marutle A, Gonzalez D, Scholl M, Almkvist O, Mousavi M, et al. Positron emission tomography imaging and clinical progression in relation to molecular pathology in the first Pittsburgh Compound B positron emission tomography patient with Alzheimer's disease. Brain. 2010;134:301-17.

54. Tsukada H, Nishiyama S, Ohba H, Kanazawa M, Kakiuchi T, Harada N. Comparing amyloid- $\beta$ deposition, neuroinflammation, glucose metabolism, and mitochondrial complex I activity in brain: a PET study in aged monkeys. Eur J Nucl Med Mol Imaging. 2014;41:2127-36.

55. Seeley WW, Crawford RK, Zhou J, Miller BL, Greicius MD. Neurodegenerative diseases target large-scale human brain networks. Neuron. 2009;62:42-52.

56. Klupp E, Grimmer T, Tahmasian M, Sorg C, Yakushev I, Yousefi BH, et al. Prefrontal hypometabolism in Alzheimer disease is related to longitudinal amyloid accumulation in remote brain regions. J Nucl Med. 2015;56:399-404.

57. Walsh DM, Selkoe DJ. A beta oligomers - a decade of discovery. J Neurochem. 2007:101:1172-84

58. Shah D, Jonckers E, Praet J, Vanhoutte G, Delgado y Palacios R, Bigot C, et al. Resting state $\mathrm{fMRI}$ reveals diminished functional connectivity in a mouse model of amyloidosis. PLoS One. 2013;8:e84241.

59. de Cristóbal J, García-García L, Delgado M, Pérez M, Pozo MA, Medina M. Longitudinal assessment of a transgenic animal model of tauopathy by FDG-PET imaging. J Alzheimers Dis. 2014;40:S79-89. 